\title{
The Hidden Persuaders: Institutions and Individuals in Economic Theory
}

by Geoffrey M. Hodgson

Version of 7 January 2002

Published in the Cambridge Journal of Economics, March 2003, 27(2), pp. 159-75.

The Business School, University of Hertfordshire, Mangrove Road, Hertford, Hertfordshire SG13 8QF, UK

Address for correspondence:

Malting House, 1 Burton End, West Wickham, Cambridgeshire CB1 6SD, UK

g.m.hodgson@herts.ac.uk

KEY WORDS: rationality, habits, institutions, downward causation, endogenous preferences

JEL classification: A1, B0, D0

\begin{abstract}
In his classic book The Hidden Persuaders, Vance Packard claimed that large corporations manipulated consumers, using advertising techniques. John Kenneth Galbraith and others have repeated a similar view. Against this, Gary Becker and George Stigler have claimed that advertising is essentially informative rather than manipulative. In contrast, it is argued here that both of these opposed accounts of human agency neglect the more subtle and undesigned processes by which institutions bear upon and mould individuals. This article proposes a concept of 'reconstitutive downward causation' in which institutions act upon individual habits and dispositions. The mechanisms involved do not fall foul of past critiques of 'holism' or methodological collectivism. This argument involves a rehabilitation of the concept of habit in social science, with far-reaching implications.
\end{abstract}




\title{
The Hidden Persuaders: Institutions and Individuals in Economic Theory
}

\author{
by Geoffrey M. Hodgson ${ }^{1}$
}

\begin{abstract}
Institutions systematically direct individual memory and channel our perceptions into forms compatible with the relations they authorize. They fix processes that are essentially dynamic, they hide their influence, and they rouse our emotions to a standardized pitch on standardized issues. Add to all this that they endow themselves with rightness and send their mutual corroboration cascading through all the levels of our information system. ... For us, the hope of intellectual independence is to resist, and the necessary first step in resistance is to discover how the institutional grip is laid upon our mind.
\end{abstract}

Mary Douglas, How Institutions Think (1987)

Vance Packard's classic best-seller The Hidden Persuaders (1957) painted a grim picture. The postwar vision of a prosperous world, in which genuine human needs were to be met by a strong, efficient and growing economy, was shattered. Packard alleged that, instead of serving human needs, the big corporations were manipulating our very wants and desires, using everything from subliminal messages to the exploitation of sexual images. Arguably, however, the social influences on our aspirations are more general, and often more subtle. In the manner discussed below, many forces that mould our personalities are undesigned rather than designed. The more deeply hidden persuaders are not the products of any corporate marketing department, or government office, but are those that emanate in some way from our social institutions and our history.

This article is about these more deeply 'hidden persuaders'. An aim is to examine how such persuasion is possible, and the possible causal mechanisms that are involved. In their research, mainstream economists often ignore the possibility that our purposes and 
preferences are reconstituted by our circumstances. Some problems with this mainstream perspective are outlined. The article moves on to consider how 'hidden persuaders' can change our preferences in fundamental ways. Some possible objections to this argument are considered. The essay concludes by reviewing the argument as a whole and suggesting a direction for future research.

\section{There's no disputing tastes}

Whatever the limitations of Packard's analysis, most theoretical models within economics admit no real persuaders at all. There are merely transmitters of information. Admittedly, a minority of economists, such as Nicolas Kaldor (1950), and especially John Kenneth Galbraith, take a different view. For them, advertising is both manipulative and wasteful. For example, in The Affluent Society, Galbraith (1969, pp. 150-2) writes:

the institutions of modern advertising and salesmanship ... cannot be reconciled with the notion of independently determined desires, for their central function is to create desires - to bring into being wants that previously did not exist ... wants can be synthesized by advertising, catalysed by salesmanship, and shaped by the discreet manipulations of the persuaders.

Galbraith is inspired by Thorstein Veblen and other economists of the old institutional school. However, the prevailing majority of economists take a different view.

The Chicago economists George Stigler and Gary Becker (1977) declare that advertising could be treated simply as ‘information'. In their classic article, they allege that 'tastes neither change capriciously nor differ importantly between people' (p. 76) they argue that 'it is neither necessary nor useful to attribute to advertising the function of changing tastes' (p. 84). Again, their argument is that advertising can be regarded as information. The consumer sought to obtain the 'knowledge ... produced by the advertising of products'. For them, such 'knowledge’ was an object of consumer choice, just like anything else.

Becker subsequently modified and extended this model in his book Accounting for Tastes (1996). Alongside 'human capital' he adds 'social capital' and other 'cultural' variables. Against any objection that individuals in former models were insensitive to their cultural and social circumstances, Becker now brings such variables into the model. Accordingly, his later model does not simply encapsulate behavioural changes in response to advertising; it also includes behavioural responses to changes in social culture as well. 
But Becker does not fulfil his promise to 'account for tastes'. We have no account of the origins or derivation of the key functional forms in his theory. They are simply assumed. In particular, as in previous models, tastes are 'immaculately conceived'. There is no accounting for the origin or nature of these tastes.

\section{Can these issues be put to the test?}

We are faced with two irreconcilable positions. Galbraith and others argue that tastes and preference functions are altered by circumstances. Becker and Stigler argue, on the contrary, that the underlying functions are unaltered - they only have to be specified properly. Can the issues in dispute be put to empirical test? The answer to this question is negative. The reason is that the standard core of utility theory is non-falsifiable.

In a neglected article, Lawrence Boland (1981) asks if any conceivable evidence would refute the standard assumptions of maximising behaviour. He then shows that such an attempt at falsification could never work. Any claim that a person is not maximising anything can always be countered by the response that the person is in fact maximising something else. Given that we can never in principle demonstrate that 'something else' (perhaps unknown to us) is not being maximised, then the theory is invulnerable to any empirical attack. To show empirically that nothing is being maximised we would have to measure every possible variable that could impinge upon humanity, from the changing of the weather to the twinkling of the stars. The maximisation assumption could be false - but it is impossible to prove that it is. While the maximisation assumption is non-falsifiable, Boland also rightly pointed out that it is not a tautology. This is because it is conceivably false. It might be the case that nothing is being maximised. But we can never know.

The problems with the maximisation argument are doubly severe when it is assumed that utility is being maximised. There is no experimental or other phenomenon that cannot in principle be 'explained' within a utility-maximising framework. Even the so-called anomalies revealed by experiments with human subjects can be explained away. If experiments show that some consumers appear to prefer a monetary reward that is less than the expected outcome, or appear to have intransitive preference orderings, then we can always get round these problems by introducing other variables. For example, evidence of apparent preference intransitivity can be explained away by taking account of the fact that the different choices take place under different conditions and at different points in time. 
Preference reversals also fail to falsify utility theory, once we accept that utility is not necessarily measured in terms of the monetary payoffs in the experiment. If we assume an added disutility associated with involvement in a risky and low probability choice, then the theory that people are maximising their utility is not overturned by these experiments. In general, a risk averse actor may not maximise expected monetary value but still be maximising expected utility. ${ }^{2}$

No evidence can, in principle, falsify the assumption that behaviour results from individuals or households maximising their utility. This has implications for both neoclassical and institutionalist views. Galbraith is wrong to presume that 'the institutions of modern advertising and salesmanship ... cannot be reconciled with the notion of independently determined desires'. If a theory is 'reconciled' with a phenomenon when it is empirically consistent with it, then the Stigler-Becker theory, involving 'independently determined' functions of desire, shows that such a reconciliation is possible. The only problem with such a reconciliation, merely hinted at by Galbraith, is the difficulty in the Stigler-Becker scheme of dealing with entirely new products.

However, is this capacity for infinite empirical reconciliation a sign of weakness or of strength? By encompassing all possible arrangements and interconnections, the important relationships and connections in particular circumstances are lost in the sea of universal possibilities. Accordingly, the universality of a theory does not necessarily mean that the theory is useful or informative.

The non-falsifiability of any theory does not necessarily mean that it is invalid or unscientific, as Karl Popper himself was later to recognise (Ackerman, 1976). What it does indicate is that the dispute between the institutionalist and the neoclassical approaches cannot be resolved simply by looking at facts. Matters of methodology and interpretation are also involved.

Of course, many proponents of utility theory would be unwilling to push the argument to extremes. They may hold to some limited version of utility theory, perhaps also in the belief that there is no adequate theoretical alternative. This more nuanced position would require a more extensive evaluation, beyond the scope of the present article. The arguments in this section are directed, instead, against those, on the one hand, who would wrongly claim that utility maximisation cannot explain some behaviour, and those, on the other hand, who are 
overly triumphalist about valid but largely barren claims that it can be applied to every possible phenomenon.

\section{Criticising the assumption of the given preference function}

The assumption of given, utility-maximising individuals (or households) has been widely criticised on theoretical grounds. One of the most famous theoretical criticisms is the argument that global, rational decision-making is impossible, given the complexity of realworld decisions and the computational limits of the human brain (Simon, 1957). Modern game theory has exposed other logical problems. In certain types of game the very definition of rationality becomes problematic (Sugden, 1991). However, all these criticisms are of maximising behaviour, rather than of the assumption of the given preference function. The following arguments address the latter issue.

We start from the contention that socio-economic systems do not simply create new products and perceptions. They also create and re-create individuals. The individual not only changes her purposes and preferences, but also revises her skills and her perceptions of her needs. Both in terms of capacities and beliefs, the individual is changed in the process.

Much follows from this important point. In particular, learning in the fullest sense is more than the discovery or reception of information; it is the reconstitution of individual capacities and preferences, tantamount to a change in individual personality. Today, we may not like a particular work of art, but after exposure to it we may acquire a taste for it. Learning can reconstitute the individual (Hodgson, 1999). In short, learning can change preferences, goals, capacities, skills and values.

Strictly, the very act of learning means that not all information is possessed and global rationality is ruled out. As Douglas Vickers (1995, p. 115) and others have acknowledged, to place learning in with the framework of the utility-maximising, rational actor, the scope of the concept has to be overly restricted. Crucially, learning is the development of the modes and means of cognition, calculation and assessment. If the methods and criteria of 'optimisation' are themselves being learned how can learning itself be optimal?

Remarkably, in the Stigler-Becker version, the preference function is already 'there', ready to deal with unpredictable and unknowable circumstances. Miraculously, the function already 'knows' its preferences for inventions yet to come; its parameter space includes variables representing the ideas and the characteristics of the commodities of the future. Mysteriously, 
it has already learned how to recognise and desire them. What does learning mean in such circumstances, when we already know much of what is to be learned? Such a conception of learning must be sorely inadequate.

Another group of criticisms emanates from recent developments in psychology. A group of psychologists emphasise that human reason is always situated in a context, and it typically relies on external objects and structures as scaffolding for ideas (Clark, 1997). It is argued that much work in economics and other social sciences is based on an unsatisfactory conception of rationality (Cosmides and Tooby, 1994; Margolis, 1994; Plotkin, 1994). In response, the temporal and the situated aspects of human reason are emphasised. In reality, reason is an iterated process of adaptive response, cued by a variety of external structures and circumstances, including social institutions.

This argument is consistent with that of David Lane et al. (1996). They argue that social interaction involves 'generative relationships' that induce changes of perception and consequent action, giving rise to new institutions and new capabilities. Whereas the given, utility-maximiser has given ends, generative relationships are about reconstitutive processes of learning within social institutions.

What I have termed the Principle of Evolutionary Explanation (Hodgson, 1998a) demands that any behavioural assumption in the social sciences must be consistent with our understanding of how human beings have evolved. Although economics is not reducible to biology, propositions in economics must be consistent with those in biology. However, the empirical and theoretical work of modern evolutionary psychologists such as Leda Cosmides and John Tooby (1994) suggests that minds essentially based on global, all-purpose, contextindependent, deliberative rationality are very unlikely to emerge through evolution. In other words, global, all-purpose rationality fails to satisfy the Principle of Evolutionary Explanation. Strikingly, Veblen (1934, p. 79) made a closely related assertion in 1898. A scientist cannot reasonably argue that rational economic man is immanently and asocially conceived. A Veblenian evolutionary perspective requires that the exclusive focus on the given agent should be abandoned.

Overall, these considerations suggest that human individuals must always be considered in their evolutionary, historical and institutional contexts. Rational deliberation is not possible except through interaction with the fabric of social institutions. It is to the question of institutions that we now turn. 


\section{The nature of institutions and habits}

Institutions are durable systems of established and embedded social rules and conventions that structure social interactions. Language, money, law, systems of weights and measures, table manners, firms (and other organisations) are all institutions. In part, the durability of institutions stems from the fact that they can usefully create stable expectations of the behaviour of others. Generally, institutions enable ordered thought, expectation and action, by imposing form and consistency on human activities. They depend upon the thoughts and activities of individuals but are not reducible to them.

Institutions both constrain and enable behaviour. However, a constraint can open up possibilities: it may enable choices and actions that otherwise would not exist. For example, the rules of language allow us to communicate and traffic rules help traffic to flow more easily and safely. But a hidden and most pervasive feature of institutions is their capacity to mould and change aspirations, instead of merely enabling them. This aspect of institutions is neglected in the 'new institutional economics'. Because institutions not only depend upon the activities of individuals but also constrain and mould them, this positive feedback gives institutions even stronger self-reinforcing and self-perpetuating characteristics.

In part, rules are embedded because people choose to follow them repeatedly. In addition, pragmatist philosophers (in the tradition of William James and John Dewey) and 'old' institutional economists (in the tradition of Thorstein Veblen, John Commons and Wesley Mitchell) argue that institutions work only because the rules involved are embedded in shared habits of thought and behaviour. From this perspective, institutions are emergent social structures, based on commonly held habits of thought: institutions are conditioned by and dependent upon individuals and their habits, but they are not reducible to them. Habits are the constitutive material of institutions, providing them with enhanced durability, power and normative authority.

Habits themselves are formed through repetition of action or thought. They are influenced by prior activity and have durable, self-sustaining qualities. Through their habits, individuals carry the marks of their own unique history. Habits are the basis of both reflective and nonreflective behaviour. For the human agent, habits are themselves means of higher deliberation and conscious resolve. 
However, habit does not mean behaviour. It is a propensity to behave in particular ways in a particular class of situations. Crucially, we may have habits that lie unused for a long time. A habit may exist even if it is not manifest in behaviour. Habits are submerged repertoires of potential behaviour; they can be triggered by an appropriate stimulus or context. ${ }^{3}$

The fact that habits may lie unused dispels a number of misconceptions and misinterpretations. Habit is not inertia, because inertia is the present effect of a movement in the immediate past. Neither is habit serially correlated behaviour; it is not 'a positive relation between past and current consumption' as Becker (1992, p. 328) put it. Because some habits can be triggered by conscious resolve, they are not the same as the behaviourist stimulusresponse mechanism or conditioned reflex.

The dependence of institutions upon habits partly roots institutions in the dispositions of individuals. Institutions are structures that face individuals, as well as stemming from individuals themselves. Accordingly, institutions are simultaneously both objective structures 'out there', and subjective springs of human agency 'in the human head'. Actor and structure, although distinct, are connected in a circle of mutual interaction and interdependence. However, the relationship is not symmetrical; structures and institutions typically precede individuals (Archer, 1995). We are all born into a world of pre-existing institutions, bestowed by history.

Institutions are the kind of structures that matter most in the social realm. They matter most because of their capacity to form and mould the capacities and behaviours of agents in fundamental ways. Instead of merely enabling individual action, the hidden and most penetrating feature of institutions is their capacity to mould and change individual dispositions and aspirations. The ways in which this can happen are discussed in the next section.

\section{Reconstitutive downward causation}

I argue here that a strong process of 'downward causation' is associated with institutions in all human societies. It is not confined to the conscious designs of the advertisers or propagandists. It emanates more widely from the ordinary routine of everyday life. In this section the notion of downward causation is introduced and discussed in general terms. It is later applied to the topic of 'hidden persuaders' under consideration here. 
The idea of 'upward causation' is already widely accepted in the social and natural sciences. Elements at a lower ontological level affect those at a higher one. For example, influenza epidemics reduce economic productivity and voting can change governments. Upward causation can be reconstitutive, because lower-level changes may alter fundamentally a higher level structure. However, reductionists are obliged to deny the possibility of reconstitutive downward causation that is being proposed here. With reconstitutive downward causation it is impossible to take the parts as given and then explain the whole. Furthermore, for reasons examined below, the notion of reconstitutive downward causation does not fall foul of past critiques of 'holism' or methodological collectivism.

The term 'downward causation' originates in psychology in the work of the Nobel psychobiologist Roger Sperry (1964, 1969). It has been discussed by Karl Popper and John Eccles among others (1977). In its literature, the notion of 'downward causation' has weak and strong forms. In a relatively weaker case, Donald Campbell (1974) sees it in terms of evolutionary laws acting on populations. He argued that all processes at the lower levels of an ontological hierarchy are restrained by and act in conformity to the laws of the higher levels. In other words, if there are systemic properties and tendencies then individual components of the system act in conformity with them. For example, a population of individual organisms is constrained by processes of natural selection.

The concept of downward causation does not rely on new or mysterious types of cause or causality. As Sperry (1991, p. 230) rightly insists: 'the higher-level phenomena in exerting downward control do not disrupt or intervene in the causal relations of the downward-level component activity'. This could usefully be termed Sperry’s Rule. It ensures that emergence, although it is associated with emergent causal powers at a higher level, does not generate multiple types or forms of causality at any single level. Any emergent causes at higher levels exist by virtue of lower-level causal processes.

Adherence to Sperry's Rule excludes any version of methodological collectivism or holism where an attempt is made to explain individual dispositions or behaviour entirely in terms of institutions or other system-level characteristics. Instead, Sperry’s Rule obliges us to explain particular human behaviour in terms of causal processes operating at the individual level, such as individual aspirations, dispositions or constraints. Higher-level factors enter in the more general explanation of the system-wide processes giving rise to those aspirations, dispositions or constraints. 
A stronger notion of downward causation, which I introduce here and describe as 'reconstitutive downward causation', involves both individuals and populations not only restrained, but also changed, as a result of causal powers associated with higher levels. ${ }^{4}$

But, at least in the context of the present discussion, how does this happen? We have to consider how the dispositions, thoughts and actions of human actors are changed. People do not develop new preferences, wants or purposes because mysterious 'social forces' control them. The argument here is that the pragmatist and institutionalist concept of habit provides part of a plausible and reconstitutive mechanism.

\section{Habits as hidden persuaders}

From the pragmatist and institutionalist perspective, habits are foundational to all thought and behaviour. As argued elsewhere, all deliberations, including rational optimisation, themselves rely on habits and rules (Hodgson, 1997). Even rational optimisation must involve rules. In turn, as suggested above, rules have to become ingrained in habits in order to be deployed by agents. Hence rationality always depends on prior habits and rules as props (Hodgson, 1988). This primary reliance on habits and rules limits the explanatory scope of rational optimisation. Hence rational optimisation can never supply the complete explanation of human behaviour and institutions, for which some theorists seem to be striving. At the centre of a more adequate explanation of human agency would be the reconstitutive processes through which habits are formed and changed.

Our habits help to make up our preferences and dispositions. When new habits are acquired or existing habits change, then our preferences alter. Dewey (1922, p. 40) thus wrote of 'the cumulative effect of insensible modifications worked by a particular habit in the body of preferences’. Alternatively, we could presume, following Gary Becker and Kevin Murphy (1988) and others, that habitual modifications are consistent with some unchanging 'metapreference' function. As argued above, empirical consistency with such a utility function might obtain. However, those that place behaviour within a meta-preference function neglect the argument that these preferences too must be grounded on learned habits and dispositions. Otherwise, as suggested above, we have no plausible story of their origin.

Consider an example of the role of habit. For reasons of cost, and a desire to minimise pollution and road congestion, a person may use the bus to travel to work. As a result of this repeated behaviour, an associated set of habits of thought and behaviour will be reinforced. 
These habits may have further repercussions. However, if the bus service is withdrawn then the individual will be obliged to use another means of travel. It may be that there is no alternative to the car. The individual will then begin to drive to work and develop another set of habits. Even if a preference for public transport is maintained, it could eventually be undermined by repeated personal car use. The change in the provision of public transport can alter preferences for that mode.

More generally, institutional changes and constraints can cause changes in habits of thought and behaviour. Institutions constrain our behaviour and develop our habits in specific ways. What does happen is that the framing, shifting and constraining capacities of social institutions give rise to new perceptions and dispositions within individuals. Upon new habits of thought and behaviour, new preferences and intentions emerge. Alfred Marshall (1949, p. 76) observed 'the development of new activities giving rise to new wants'. But we need to know how this happens. Veblen (1899, p. 190, emphasis added) was more specific about the psychological mechanisms involved: 'The situation of today shapes the institutions of tomorrow through a selective, coercive process, by acting upon men's habitual view of things'.

We are typically constrained in our actions. Accordingly, we acquire habits consistent with the operation of these constraints. Even when these constraints are removed, habits dispose us to act or think in the same old way. As the institutional economist John Commons (1934, p.701) remarked: 'when customs change ... then it is realized that the compulsion of custom has been there all along, but unquestioned and undisturbed.’

The crucial point in the argument here is to recognise the significance of reconstitutive downward causation on habits, rather than merely on behaviour, intentions or beliefs. Clearly, the definitional distinction between habit (as a propensity or disposition) and behaviour (or action) is essential to make sense of this statement. Once habits become established they become a potential basis for new intentions or beliefs.

But a second point is also of vital significance. It is a central tenet of the pragmatist philosophical and psychological perspective to regard habit and instinct as foundational to the human personality. Reason, deliberation and calculation emerge only after specific habits have been laid down; their operation depends upon such habits. In turn, the development of habits depends upon prior instincts. Instincts, as typically defined, are inherited. Accordingly, reconstitutive downward causation upon instincts is not possible. ${ }^{5}$ 
The ongoing acquisition and modification of habits is central to individual human existence. For example, much deliberative thought is dependent on, as well as being coloured by, acquired habits of language. In addition, to make sense of the world we have to acquire habits of classification and habitually associated meanings. The crucial point is that all action and deliberation depend on prior habits that we acquire during our individual development. Hence habits have temporal and ontological primacy over intention and reason. As we have seen, reconstitutive downward causation works by creating and moulding habits. Habit is the crucial and hidden link in the causal chain.

Accordingly, as long as we can explain how institutional structures give rise to new or changed habits, then we have an acceptable mechanism of reconstitutive downward causation. In contrast, we cannot identify any causal mechanism where institutions lead directly to the reconstitution of purposes or beliefs. Institutions may lead directly to changes in some intentions, but only by acting as non-reconstitutive influences or constraints. For example, we decide to drive within the speed limit because we see a police car on the motorway. The particular intention is explained in terms of the existing preference to avoid punishment. This explanation does not itself involve a reconstitutive process. Clearly, any attempt to explain changes in intentions through intentions alone must assume a fixed subset of (meta-) preferences behind the expedient changes of intention and action. In contrast, to provide a reconstitutive causal mechanism, we have to point to factors that are foundational to purposes, preferences and deliberation as a whole. This is where habits come in.

As a result, institutions are social structures with the capacity for reconstitutive downward causation, acting upon ingrained habits of thought and action. Powers and constraints associated with institutional structures can encourage changes in thought and behaviour. In turn, upon these repeated acts, new habits of thought and behaviour emerge. It is not simply the individual behaviour that has been changed: there are also changes in habitual dispositions. In turn, these are associated with changed individual understandings, purposes and preferences. We now consider some further examples of the processes involved. ${ }^{6}$

\section{Hidden mechanisms of persuasion}

A number of explanations are consistent with this general principle of habitual reconstitution. For example, the fable of 'sour grapes' speaks precisely of people declaring a change of preferences because of ambition frustrated by circumstances (Elster, 1983). These 
circumstances could include structures or institutions. New habits would then arise, in accord with the changed preferences. Similarly, the theory of cognitive dissonance (Festinger, 1957) explains that when people are faced with a difficult choice between alternative courses of action their perception of the alternatives is adjusted to render one of them more acceptable. This is often done by imitating and acquiring the norms and perceptions of others (Hodgson, 1988). This can result in the transmission of habits of thought and behaviour from one person to another.

There is an established postwar literature in social psychology on mechanisms of power, social influence, individual compliance and opinion change (Kelman, 1958, 1961; Tedeschi, 1972, 1974). Much of this literature considers mechanisms that are broadly similar to the idea of reconstitutive downward causation. However, when considering the mechanisms though which individuals change their preferences or dispositions, psychologists sometimes put emphasis on a behaviourist idea of conditioning. As suggested above, the earlier, pragmatist notion of habit provides a significantly different, and arguably more adequate, approach. Instead of a behaviourist emphasis on a predictive model of human behaviour, the aim of a habit-based analysis is to understand the formation and grounding of individual preferences and beliefs. Others such as Herbert Kelman (1961, pp. 63-5) put emphasis on behaviour being internalised because it is consistent with the individual's 'value system' or it involves 'the evaluation and acceptance of induced behavior in rational grounds.' We can then go further and discuss the habitual bases of those evaluations and rational calculations. Much of this literature on social influence and compliance points to mechanisms of reconstitutive downward causation that can be recast in pragmatist and institutionalist terms.

Another body of literature from psychology that can be reinterpreted in the terms proposed here is the empirical and theoretical work on obedience to authority (Milgram, 1974; Kelman and Hamilton, 1989). It is proposed that obedience to authority can result from several processes. It may be a direct effect of rewards for compliance or of punishments for noncompliance. Alternatively, it may result from a deeper identification with the values of those in authority. In the former case, reconstitutive downward causation will occur only if compliance eventually gives rise to habits of thought or behaviour consistent with obedience. In the latter case, to minimise unease and self-doubt, an original habit of deference to authority might be expanded into a reconstitutive acceptance of the norms and values of those in power. 
It is often underestimated that people have a need for meanings and explanations in their everyday lives. In all cultures known to anthropology there is evidence of the universal human hunger for meaning. It is fed by religion, by ritual, through playful curiosity or by modern science. In meeting our desire for meaning we acquire the habits of thought and behaviour of our culture. As Mary Douglas and Baron Isherwood (1980) have argued, much of consumer behaviour acquires its meaning through social interaction. In establishing such meanings we interpret, imitate and compare with the behaviour of others. We acquire habits of thought and behaviour that dovetail with those of the culture as a whole. These are the social mechanisms by which the habits that are associated with social institutions are transmitted and reinforced to the individuals involved. ${ }^{7}$

If we take the arguments discussed above from modern psychology on situated cognition seriously, then we must recognise that our aspirations and choices are cast in institutional moulds (Clark, 1997; Lane et al. 1996). Much of our deliberation takes place within and through social institutions. We use institutions and their routines as templates in the construction of our habits, intentions and choices.

Consequently, reconstitutive downward causation is an indelible feature of social life. Yet it is absent from mainstream economics. Many economists, including Becker (1996, p. 225) describe situations where individual purposes and choices are moulded as 'brainwashing'. This involves a neglect of the undesigned institutional processes of persuasion. The mechanisms of reconstitutive downward causation are far more widespread and subtle than the overt 'brainwashing' of individuals. Typical of many economists, Becker recognises nothing in between 'brainwashing' on the one hand, and 'free choice' based on given preference functions, on the other. The truth is that most of social behaviour lies between these two extremes.

On the other hand, Galbraith and other critics of mainstream economics have often focused too much on advertising, to the neglect of the subtler and typically undesigned institutional mechanisms of persuasion. It is important to theorise the middle grounds between brainwashing or advertising, and 'free choice'.

\section{Some possible theoretical avenues and illustrations}

It has been argued here that the causal processes of reconstitution discussed here are not mysterious 'social forces' but plausible psychological mechanisms of imitation, conformism, 
conditioning and cognition. The basic contention here is that these mechanisms are subtle and pervasive. Their fuller analysis will have to await further a study. Instead let us briefly consider some further implications, in terms of the type of economic theory that can be sustained by this approach.

In the 1970s, the name of James Duesenberry could still be found in some of the recommended economics textbooks. Duesenberry (1949) developed a model of consumer behaviour, inspired by the work of Veblen and based on habits and learning effects. In his model, as incomes rose, people acquired new habits of consumption that persisted, even if incomes later fell. Their tastes and preferences altered as they acquired new lifestyles. This model of aggregate consumer behaviour performed well in several econometric tests. Nevertheless, Duesenberry's model fell out of favour, not because it performed badly in statistical tests, but because it was not based on the mainstream idea of the rational, utilitymaximising consumer (Green, 1979). Today, few students of macroeconomics will learn of Duesenberry's theory.

Yet this type of approach remains as vital as ever. Notably, in a review of the relationship between economics and psychology, Matthew Rabin (1998, p. 13) argues that an understanding that people are often more sensitive to changes than to absolute levels suggests such factors as habitual levels of consumption should be incorporated into analysis.

Another possible theoretical illustration of the general approach noted here is Walter Runciman's (1972) theory of relative deprivation. It is quite similar to Duesenberry's theory. According to Runciman, the capacity to accept and endure deprivation is positively correlated to the incidence of that same deprivation in that person's peer group. As a result, workers will often begin to demand higher wages when they see the wages of a related group of workers rising significantly above theirs. This theory is also consistent with the idea that preferences and expectations are formed in a social context.

Another implication concerns the explanation of the existence of firms. Oliver Williamson (1975) has followed Ronald Coase (1937) in putting the burden of the argument for the existence of the firm on the proposition that transaction costs in viable firms are lower than they would be if production were coordinated through the market. In this argument the individual is taken as given: social institutions bear upon individuals simply via the costs they impose. However, once we abandon the idea of the given individual, then we can give much greater prominence to the possibility that, in becoming a part of a firm, workers develop 
capacities and allegiances that result from their new institutional environment. Crucial to this institutional explanation would be the concept of corporate culture and its role in reconstituting the goals and capabilities of the workforce. The firm would have a reconstitutive effect upon individuals (Hodgson, 1998b).

A predictable objection to all these theoretical initiatives is that they can all be fitted into more sophisticated models of the individual utility-maximiser, perhaps along the lines of Becker (1996). After all, Becker (1992) and others claim that they can deal with culture, habit, relative deprivation and all the other issues raised here. It is evident that their models can embrace every possibility. However, the dispute between neoclassical and institutionalist views is not primarily a question of whether the data can be accommodated into the theory. The debate is on the question of theoretical coherence and adequate explanation.

\section{The return of habit}

The mechanisms of reconstitutive downward causation proposed here depend on a rehabilitated concept of habit. However, although the concept of habit was once central to social and political philosophy, it has been eliminated from large parts of contemporary social science. Habit and custom were dropped from sociology during the transition from Max Weber to Talcott Parsons (Camic, 1986; Hodgson, 2001b).

One reason for this rejection has been the misconception that habit involves a mechanical conception of human behaviour. Parsons (1935) in particular saw no essential distinction between the pragmatist stress on habit and the emerging behaviourist psychology in which the emphasis was on behavioural conditioning. He was very mistaken. Behavioural psychologists stress the conditioning of overt behaviour, while the pragmatists and instinct psychologists saw habits as bundles of potentialities and dispositions, to be potentially triggered by small or large perceptions or events. Upon this repertoire of habits there is scope for decision and will (Dewey, 1922).

Furthermore, habits exist at different levels of consciousness and deliberation. There can be context-dependent cascades of triggered habits, with possible high sensitivity to small changes of circumstance. Habit does not deny choice. Different sets of habits may give rise to competing preferences. A choice is then made, and this choice may itself involve a further cluster of habitual interpretations or predispositions. 
It is beyond the scope of this essay to enquire into the difficult philosophical question of the freedom of the will. It is simply point out that the act of deliberation among a tangled complex of interlayered habits is at least as free as the utility-maximising robot of mainstream economics. Indeed, it is a myth that any individual who is programmed to maximise his or utility according to some fixed function is free. Mainstream economics wants it both ways: it wants the ideology of individual freedom and a model of predictable human choice. Instead, it is proposed here that, on the one hand, choice is a largely unpredictable outcome of the complex human nervous system, situated in a complex, open and changing environment. On the other hand, our inheritance, upbringing and circumstances affect our choices. Human agency is neither uncaused nor generally predictable.

The pragmatist philosophers who influenced Veblen and the institutionalists broke from the overly rationalistic and deliberative conception of action that had dominated Western thought since the Enlightenment. In the deliberative conception of action, beliefs are the drivers of deliberation and action, perhaps later to be modified in the light of experience. However, the causal origins of beliefs themselves are inadequately explained. By contrast, in the pragmatist (or habit-based) conception, 'the essence of belief is the establishment of habit' (Peirce, 1878, p. 294).

A hallmark of the habit-based conception of action is that the individual's preferences are no longer taken as given. Furthermore, beliefs may change, not simply as a result of receiving information, but also because habitual mechanisms of interpretation may alter. In contrast to the pervasive idea of the given individual, the individual is formed and reconstituted in an ongoing process. Institutions matter in both cases. But in the habit-based conception they can also lead eventually to new habits and new preferences or beliefs.

In order to give a more complete, habit-based picture, some account of the development of the original habits of the individual is required. Acquired habits are themselves founded upon inherited instincts. Instincts trigger behaviours and give rise to habits. Nevertheless, instinctive propensities are heavily diverted or overlaid by habits and beliefs acquired through interaction with others in a social culture. Accordingly, habit is a bridging element between the biological, psychological and social domains.

While natural selection operates upon inherited instincts, other evolutionary processes of selection operate at the cultural or social level. This is the 'natural selection of institutions' (Veblen, 1899, p. 188). In the social sphere, habits have genotypical qualities, although they 
are not nearly as durable as the biotic genes. However, unlike the replication of DNA, habits do not directly make copies of themselves. Instead they replicate indirectly (Hodgson, 2001a). They impel behaviour that is, in turn, consciously or unconsciously imitated by others. Eventually, this copied behaviour becomes rooted in the habits of the imitator, thus transmitting from individual to individual an imperfect copy of each habit by an indirect route. Like natural selection, cultural selection works at the level of the population, not simply of the individual. It exerts 'downward causation' by exploiting mechanisms of imitation, conformism and constraint.

\section{Some conclusions and implications}

The standard mainstream view of the utility-maximising human agent has come under much criticism. The concern of the present paper is both to highlight some less familiar criticisms and to move towards the construction of an alternative approach. It has been argued that the possibility that a model of a utility-maximising agent might fit every possible circumstance is a weakness rather than a strength. The non-falsifiability of the model requires us to focus on matters of theoretical rather than empirical adequacy.

Furthermore, the idea of the given individual is unable to provide an adequate account of its own origin, either in terms of evolution or of individual human development. The Principle of Evolutionary Explanation requires that all assumptions concerning human behaviour should be consistent with our knowledge and understanding of human evolution. Arguments and evidence from modern psychology suggest that the standard model of the utility-maximising actor fails in this regard.

Some time ago, Duesenberry developed a model of consumer behaviour in which habit and habit formation were at the centre. Mainstream economists have often discussed habit, but by making it an outcome of rational choice. On the contrary, it has been argued here that habits are developmentally and practically prior to any form of conscious reasoning. Even rational choices require habits as a substratum.

The line of theoretical research suggested here is to develop an enhanced picture of the role of habit in economic life. Several models of habit do exist, but generally they see habit as based upon, and derivable from, rational behaviour (Lluch, 1974; Phlips and Spinnewyn, 1984; Becker and Murphy, 1988; Becker, 1992). Remarkably, despite the uncountable number of mathematical models of human behaviour in economics, very few examples are 
based on habit. There are two notable exceptions: Arrow (1986) and Becker (1962). ${ }^{8}$ Apart from this, little else has been tried. However, these earlier precedents suggest some fruitful possibilities for habit-based analysis, if it were pursued.

With the theoretical framework proposed here, it may be possible to overcome the dilemma between methodological individualism and methodological collectivism. By acting not directly on individual decisions, but on habitual dispositions, institutions exert downward causation without reducing individual agency to their effects. Furthermore, upward causation, from individuals to institutions, is still possible, without assuming that the individual is given or immanently conceived. Explanations are reduced neither to individuals nor to institutions alone.

One possible objection to this line of research would be to suggest that the assumption of agents with such institutional influences on their preference functions would be hopelessly complicated and intractable. Accordingly, it could be argued, it is necessarily to simplify matters and assume agents with preference functions that are given. Any assumption of 'endogenous' preferences must take some factors as given, so why not assume that preferences have this status?

To respond to this argument it is necessary to show what is possible within the framework discussed above. This is a matter for future research and a full answer cannot be given here. Nevertheless, such research can examine the following hypothesis: in some circumstances, the assumption of malleable preferences may simplify matters rather than complicate them. It may be conjectured that the process of reconstitutive downward causation may provide a degree of durability and stability in institutional structure that is not explained adequately in standard models. The circular, positive feedback from institution to individuals and from individuals to institutions can help to enhance the durability of the institutional unit. What would then be theorised is the self-reinforcing institutional structure. Accordingly, within an institutional structure, it may be possible to show that malleable preferences lead to stable emergent properties. These properties may exist not despite, but because of, malleable preferences. This not a proven result but a plausible conjecture that remains to be explored.

No less radical are the implications for the theory of economic welfare. One reason for choosing the model of the utility-maximising individual is that it dovetails easily with the standard ideological assumption that the individual is generally the best judge of his or her welfare. But if preference functions are themselves capable of change then this standard 
approach to welfare economics is weakened. What individuals judge to be the best for them today is not necessarily what they will judge tomorrow. The standard welfare-theoretic basis of much economic policy is thus called into question (Gintis, 1972, 1974; Steedman, 1980).

Economics will not develop by ducking these questions. For those inclined to accept some of the above criticism of mainstream presuppositions, there is a huge research agenda ahead. Clearly, this involves empirical as well as theoretical work. To understand fully the ways in which human agents are moulded by institutions we have to look at particular cultures, circumstances and cases. An understanding of the world requires theory, but it cannot be obtained by theory alone. 


\section{References}

Ackerman, Robert (1976) The Philosophy of Karl Popper (Amherst, MA: University of Massachusetts Press).

Archer, Margaret S. (1995) Realist Social Theory: The Morphogenetic Approach (Cambridge: Cambridge University Press).

Arrow, Kenneth J. (1986) 'Rationality of Self and Others in an Economic System', Journal of Business, 59(4.2), October, pp. S385-S399. Reprinted in Eatwell, John, Milgate, Murray and Newman, Peter (eds) (1987) The New Palgrave Dictionary of Economics, (London: Macmillan), vol. 2.

Becker, Gary S. (1962) 'Irrational Behavior and Economic Theory', Journal of Political Economy, 70(1), February, pp. 1-13.

Becker, Gary S. (1992) 'Habits, Addictions and Traditions’, Kyklos, 45, Fasc. 3, pp. 327-46.

Becker, Gary S. (1996) Accounting for Tastes (Cambridge, MA: Harvard University Press).

Becker, Gary S. and Murphy, Kevin M. (1988) ‘A Theory of Rational Addiction', Journal of Political Economy, 96(4), pp. 675-700.

Boland, Lawrence A. (1981) 'On the Futility of Criticizing the Neoclassical Maximization Hypothesis', American Economic Review, 71(5), December, pp. 1031-36. Reprinted in Boland, Lawrence A. (1996) Critical Economic Methodology: A Personal Odyssey (London and New York: Routledge).

Camic, Charles (1986) 'The Matter of Habit', American Journal of Sociology, 91(5), pp. 1039-87.

Campbell, Donald T. (1974) “"Downward Causation” in Hierarchically Organized Biological Systems', in Ayala, Francisco J. and Dobzhansky, Theodosius (eds) (1974) Studies in the Philosophy of Biology (London, Berkeley and Los Angeles: Macmillan and University of California Press), pp. 179-86.

Clark, Andy (1997) Being There: Putting the Brain, Body and World Together Again (Cambridge, MA: MIT Press).

Coase, Ronald H. (1937) ‘The Nature of the Firm’, Economica, 4, November, pp. 386-405. 
Commons, John R. (1934) Institutional Economics - Its Place in Political Economy (New York: Macmillan).

Cosmides, Leda and Tooby, John (1994) 'Beyond Intuition and Instinct Blindness: Towards an Evolutionary Rigorous Cognitive Science’, Cognition, 50(1-3), April-June, pp. 41-77.

Dewey, John (1922) Human Nature and Conduct: An Introduction to Social Psychology, 1st edn. (New York: Holt).

Douglas, Mary (1987) How Institutions Think (London and Syracuse: Routledge and Kegan Paul and Syracuse University Press).

Douglas, Mary and Isherwood, Baron (1980) The World of Goods: Towards an Anthropology of Consumption (Harmondsworth: Penguin).

Duesenberry, James S. (1949) Income, Saving and the Theory of Consumer Behavior (Cambridge MA: Harvard University Press).

Elster, Jon (1983) Sour Grapes: Studies in the Subversion of Rationality (Cambridge: Cambridge University Press).

Festinger, Leon (1957) A Theory of Cognitive Dissonance (Stanford, CA: California University Press).

Galbraith, John Kenneth (1969) The Affluent Society, 2nd. edn. (London: Hamilton).

Gintis, Herbert (1972) 'A Radical Analysis of Welfare Economics and Individual Development', Quarterly Journal of Economics, 86(4), November, pp. 572-99.

Gintis, Herbert (1974) 'Welfare Criteria With Endogenous Preferences: The Economics of Education’ International Economic Review, 15(2), June, pp. 415-30.

Green, Francis (1979) 'The Consumption Function: A Study in the Failure of Positive Economics', in Green, Francis and Nore, Petter (1979) Issues in Political Economy: A Critical Approach (London: Macmillan), pp. 33-60.

Hodgson, Geoffrey M. (1988) Economics and Institutions: A Manifesto for a Modern Institutional Economics (Cambridge and Philadelphia: Polity Press and University of Pennsylvania Press).

Hodgson, Geoffrey M. (1997) 'The Ubiquity of Habits and Rules', Cambridge Journal of Economics, 21(6), November, pp. 663-84. 
Hodgson, Geoffrey M. (1998a) 'The Approach of Institutional Economics', Journal of Economic Literature, 36(1), March, pp. 166-92.

Hodgson, Geoffrey M. (1998b) 'Competence and Contract in the Theory of the Firm', Journal of Economic Behavior and Organization, 35(2), April, pp. 179-201.

Hodgson, Geoffrey M. (1999) Economics and Utopia: Why the Learning Economy is Not the End of History (London and New York: Routledge).

Hodgson, Geoffrey M. (2001a) 'Is Social Evolution Lamarckian or Darwinian?’ in Laurent, John and Nightingale, John (eds) Darwinism and Economics (Cheltenham: Edward Elgar) pp. 87-118.

Hodgson, Geoffrey M. (2001b) How Economics Forgot History: The Problem of Historical Specificity in Social Science (London and New York: Routledge).

Hodgson, Geoffrey M. (2002) 'Reconstitutive Downward Causation: Social Structure and the Development of Individual Agency' in Fullbrook, Edward (ed.) (2002) Intersubjectivity in Economics: Agents and Structures (London and New York: Routledge), pp. 159-80.

Hodgson, Geoffrey M. and Knudsen, Thorbjørn (unpublished) 'The Complex Evolution of a Simple Traffic Convention: The Functions and Implications of Habit', University of Hertfordshire, mimeo, 2001.

James, William (1890) The Principles of Psychology, 1st edn. (New York: Holt).

Kaldor, Nicholas (1950) 'The Economic Effects of Advertising', Review of Economic Studies, 18(1), pp. 1-27.

Kelman, Herbert C. (1958) 'Compliance, Identification, and Internalization: Three Processes of Attitude Change’, Journal of Conflict Resolution, 2, pp. 51-60.

Kelman, Herbert C. (1961) 'Processes of Opinion Change’, Public Opinion Quarterly, 25, pp. 57-78.

Kelman, Herbert C. and Hamilton, V. Lee (1989) Crimes of Obedience: Toward a Social Psychology of Authority and Responsibility (New Haven: Yale University Press).

Lane, David, Malerba, Franco, Maxfield, Robert and Orsenigo, Luigi (1996) 'Choice and Action', Journal of Evolutionary Economics, 6(1), pp. 43-76. 
Lluch, C. (1974) 'Expenditures, Savings and Habit Formation', International Economic Review, 15, pp. 786-97.

Margolis, Howard (1994) Paradigms and Barriers: How Habits of Mind Govern Scientific Beliefs (Chicago: University of Chicago Press).

Marshall, Alfred (1949) The Principles of Economics, 8th (reset) edn. (1st edn. 1890) (London: Macmillan).

Milgram, Stanley (1974) Obedience to Authority: An Experimental View (New York and London: Harper and Row, and Tavistock).

Murphy, James Bernard (1994) 'The Kinds of Order in Society', in Mirowski, Philip (ed.) (1994) Natural Images in Economic Thought: Markets Read in Tooth and Claw (Cambridge and New York: Cambridge University Press), pp. 536-82.

Packard, Vance (1957) The Hidden Persuaders (London: Longmans, Green).

Parsons, Talcott (1935) 'Sociological Elements in Economic Thought, Parts I \& II', Quarterly Journal of Economics, 49, pp. 414-53, 646-67. Reprinted in Camic, Charles (ed.) (1991) Talcott Parsons: The Early Essays (Chicago: University of Chicago Press).

Phlips, Louis and Spinnewyn, F. (1984) 'True Indexes and Rational Habit Formation', European Economic Review, 24, pp. 209-23.

Peirce, Charles Sanders (1878) 'How to Make Our Ideas Clear', Popular Science Monthly, 12, January, pp. 286-302. Reprinted in Peirce, Charles Sanders (1958) Selected Writings (Values in a Universe of Chance), edited with an introduction by Philip P. Wiener (New York: Doubleday).

Plotkin, Henry C. (1994) Darwin Machines and the Nature of Knowledge: Concerning Adaptations, Instinct and the Evolution of Intelligence (Harmondsworth: Penguin).

Popper, Karl R. and Eccles, John C. (1977) The Self and Its Brain (Berlin: Springer International).

Rabin, Matthew (1998) 'Psychology and Economics', Journal of Economic Literature, 36(1), March, pp. 11-46.

Runciman, Walter G. (1972) Relative Deprivation and Social Justice (Harmondsworth: Pengion). 
Simon, Herbert A. (1957) Models of Man: Social and Rational. Mathematical Essays on Rational Human Behavior in a Social Setting (New York: Wiley).

Smith, Vernon L. (1982) 'Microeconomic Systems as an Experimental Science', American Economic Review, 72(5), December, pp. 923-55.

Sperry, Roger W. (1964) Problems Outstanding in the Evolution of Brain Function (New York: American Museum of Natural History).

Sperry, Roger W. (1969) 'A Modified Concept of Consciousness', Psychological Review, 76(6), pp. 532-6.

Sperry, Roger W. (1991) 'In Defense of Mentalism and Emergent Interaction', Journal of Mind and Behavior, 12(2), pp. 221-46.

Steedman, Ian (1980) 'Economic Theory and Intrinsically Non-Autonomous Preferences and Beliefs', Quaderni Fondazione Feltrinelli, no. 7/8, pp. 57-73. Reprinted in Steedman, Ian (1989) From Exploitation to Altruism (Cambridge: Polity Press).

Stigler, George J. and Becker, Gary S. (1977) ‘De Gustibus Non Est Disputandum’, American Economic Review, 76(1), March, pp. 76-90.

Sugden, Robert (1991) 'Rational Choice: A Survey of Contributions from Economics and Philosophy’, Economic Journal, 101(4), July, pp. 751-85.

Tedeschi, James T. (ed.) (1972) The Social Influence Processes (Chicago: Aldine-Atherton).

Tedeschi, James T. (ed.) (1974) Perspectives on Social Power (Chicago: Aldine-Atherton).

Veblen, Thorstein B. (1899) The Theory of the Leisure Class: An Economic Study in the Evolution of Institutions (New York: Macmillan).

Veblen, Thorstein B. (1934) Essays on Our Changing Order, ed. Leon Ardzrooni (New York: The Viking Press).

Vickers, Douglas (1995) The Tyranny of the Market: A Critique of Theoretical Foundations (Ann Arbor: University of Michigan Press).

Williamson, Oliver E. (1975) Markets and Hierarchies: Analysis and Anti-Trust Implications: A Study in the Economics of Internal Organization (New York: Free Press). 


\section{Footnotes}

${ }^{1}$ This paper is based on the author's inaugural lecture, as Research Professor in Economics, at the University of Hertfordshire on 16 March 2000. He is grateful to Masahiko Aoki, Victoria Chick, Stephen Dunn, Ben Fletcher, Chris Fuller, Avner Greif, Paul Milgrom, Giles Slinger, Ian Steedman, two anonymous referees and others for comments, discussions and helpful criticisms.

2 Experimental economists such as Smith (1982) and others have addressed the problem of the possible absence of a linear correlation between utility and monetary payoff. Smith proposes a number of 'precepts' of experimental assumption and design constituting an 'induced value procedure'. But Smith (p. 929) himself is the first to admit that these precepts cannot guarantee any correspondence between observable monetary rewards and preferences that are 'not directly observable'.

3 The misconception of habit as behaviour led Dewey (1922) to emphasise repeatedly that habit is an acquired disposition or propensity. The conception of a habit as a propensity is also found in works such as Camic (1986), James (1890), Margolis (1994), Murphy (1994) and others. The works of James (1890) and Dewey (1922) remain two of the best accounts of the nature of habit as understood here.

${ }^{4}$ Sperry (1991, pp. 230-1) also suggests a strong interpretation of downward causation. He recognises, for example, that 'higher cultural and other acquired values have power to downwardly control the more immediate, inherent humanitarian traits.'

${ }^{5}$ However, 'downward causation' upon instincts, in the weaker dense of Campbell (1974), is possible, simply because instincts, like other human features, exist and evolve in consistency with higher level principles, such as the laws of evolution.

${ }^{6}$ See also Hodgson (2002). In Hodgson and Knudsen (unpublished) the processes of habit formation and reconstitutive downward causation are modelled in a computer simulation.

7 This account of habit formation is admittedly sketchy and needs much more refinement. It has to be shown how behaviours are identified, interpreted, understood and replicated, 
before habits themselves are 'transmitted' from one agent to another. This aspect of the analysis awaits further elaboration.

${ }^{8}$ When Becker published his 1962 paper he was at the Columbia University. This was the institution where Mitchell had taught for many years and where institutional economics had a lingering influence. Becker moved to Chicago in 1969. From then on, his work was populated with utility maximisers rather than creatures founded upon habit. In this choice of theoretical approach, perhaps Becker too was moulded by institutional circumstances. 